\title{
Primary Afferent Terminals in Spinal Cord Express Presynaptic AMPA Receptors
}

\author{
Chun-Rong Lu, Se Jin Hwang, Kristen D. Phend, Aldo Rustioni, and Juli G. Valtschanoff \\ Department of Cell and Developmental Biology, University of North Carolina, Chapel Hill, North Carolina 27599
}

Larger dorsal root ganglion neurons are stained by an antibody for the $\mathrm{C}$ terminus of glutamate receptor subunit 2 (GluR2) and GluR3 (GluR2/3) rather than by an antibody for GluR4. In dorsal roots, anti-GluR2/3 stains predominantly myelinated fibers; anti-GluR4 or anti-GluR2/4 stains predominantly unmyelinated fibers. In the dorsal horn, puncta immunopositive for synaptophysin and GluR2/3 are predominantly in laminas III and IV, whereas puncta immunopositive for synaptophysin and GluR4 or GluR2/4 are predominantly in laminas I and II. Puncta immunopositive for GluR2/3 costain with the B subunit of cholera toxin, whereas puncta immunopositive for GluR2/4 costain with isolectin B4 after injections of these tracers in the sciatic nerve. No puncta costain with calcitonin gene-related peptide and AMPA receptor subunits. Electron microscopy indicates that AMPA receptor-immunopositive terminals are more numerous than suggested by confocal microscopy. Of all synapses in which immunostaining is presynaptic, postsynaptic, or both, the percentage of presynaptic immunostain is $~ 70 \%$ with antiGluR4 or anti-GluR2/4 (in laminas I-III), 25-30\% with anti-
GluR2/3 (in laminas III and IV), and 5\% with anti-GluR2 (in laminas I-III). Because of fixation constraints, the types of immunostained terminals could be identified only on the basis of morphological characteristics. Many terminals immunostained for GluR2/3, GluR4, or GluR2/4 have morphological features of endings of primary afferents. Terminals with morphological characteristics of presumed GABAergic terminals are also immunostained with anti-GluR2/4 and anti-GluR4 in laminas I and II and with anti-GluR2/3 in laminas III and IV. The conspicuous and selective expression of presynaptic AMPA receptor subunits may contribute to the characteristic physiological profile of different classes of primary afferents and suggests an important mechanism for the modulation of transmitter release by terminals of both myelinated and unmyelinated primary afferents.

Key words: glutamate receptors; autoreceptors; dorsal horn; synaptic modulation; dorsal root ganglion; primary afferent depolarization
Glutamate activates postsynaptic ionotropic glutamate receptors, identified primarily on the basis of their responsiveness to agonists, usually referred to in their abbreviated forms as AMPA, kainate, and NMDA. Ionotropic glutamate receptors may also modulate neurotransmitter release via a presynaptic mechanism (Westbrook and Lothman, 1983; Raiteri et al., 1992; Smirnova et al., 1993; Picaud et al., 1995; Chittajallu et al., 1996; Meir et al., 1999; Khack and Henderson, 2000). Presynaptic ionotropic glutamate receptors (PIGRs), including AMPA receptors (AMPARs), can regulate the release of glutamate (Pittaluga et al., 1997; McDermott et al., 1999; Caicedo et al., 2000; Casado et al., 2000; Fabian-Fine et al., 2000; Friedman and Strowbridge, 2000; Patel et al., 2001; Schmitz et al., 2001; Lee et al., 2002) and of other neurotransmitters (Bureau and Mulle, 1998; Glitsch and Marty, 1999; Paquet and Smith, 2000; Satake et al., 2000; Cossart et al., 2001).

Numerous dorsal root ganglion (DRG) neurons express glutamate receptors (Huettner, 1990; Shigemoto et al., 1992; Partin et al., 1993; Sato et al., 1993; Liu et al., 1994; Petralia et al., 1994; Watanabe et al., 1994; Chambille and Rampin, 2002; Marvizón et

\footnotetext{
Received June 21, 2002; revised July 29, 2002; accepted Aug. 8, 2002.

This work was supported by National Institutes of Health Award NS-12440 (A.R.) We thank A. Burette and N. Kramarcy for their help with confocal microscopy and R. J. Weinberg for his encouragement and careful reading of this manuscript.

Correspondence should be addressed to Chun-Rong Lu, Department of Cell and Developmental Biology, CB 7090, University of North Carolina, Chapel Hill, NC 27599. E-mail: chunrong_lu@med.unc.edu.

S. J. Hwang's present address: Department of Anatomy, College of Medicine, Hanyang University, Seoul, 133-791 South Korea.

Copyright (C) 2002 Society for Neuroscience $0270-6474 / 02 / 229522-08 \$ 15.00 / 0$
}

al., 2002). Peripheral transport of glutamate receptors is suggested by immunopositivity for NMDA, kainate, or AMPA receptors in nerve fibers and endings in the skin (Carlton et al., 1995; Coggeshall and Carlton, 1998; Carlton and Coggeshall, 1999; Kinkelin et al., 2000). These receptors can be activated by peripheral application of glutamate and may contribute to sensitization after injury (Lawand et al., 1997; Davidson and Carlton, 1998; Du et al., 2001).

NMDA receptors in terminals of primary afferents in the spinal cord may act as autoreceptors (Liu et al., 1994) and facilitate the release of neuropeptides by the same terminals (Liu et al., 1997). Presynaptic kainate receptors in primary afferent terminals, first suggested by selective depolarization of $\mathrm{C}$-fibers by kainate (Davies et al., 1979; Agrawal and Evans, 1986) and by activation of nociceptive afferents after skin exposure to kainate (Ault and Hildebrand, 1993), can modulate the release of neurotransmitters from primary afferent terminals onto dorsal horn neurons (Lee et al., 1999; Kerchner et al., 2001).

AMPAR immunostaining decreases after dorsal rhizotomy (Carlton et al., 1998), and recent electrophysiological data show activation of presynaptic AMPARs at or near central terminals of DRG neurons of perinatal rats (Lee et al., 2002). Here, we used fixation conditions designed to maximize the detection of presynaptic AMPARs and demonstrate that subunits of this receptor are expressed in numerous terminals in the dorsal horn, which are, at least in part, endings of primary afferents. We also show that expression of presynaptic AMPAR subunits is not uniform but is very selective in terminals of different types of primary afferents in superficial laminas of the dorsal horn. 


\section{MATERIALS AND METHODS}

Animal care and treatment were according to the University of North Carolina, Institutional Animal Care and Use Committee and National Institutes of Health guidelines. Male Sprague Dawley rats (250-350 gm; Charles River, Raleigh, NC) anesthetized with sodium pentobarbital (60 $\mathrm{mg} / \mathrm{kg}$, i.p.) were perfused with heparinized (500 IU heparin sodium) saline, followed by fixative. The fixative was a $0.5,1$, or $4 \%$ solution of paraformaldehyde (PF) in phosphate buffer $(\mathrm{PB}, 0.1 \mathrm{M}, \mathrm{pH} 7.4)$ for light microscopy (LM), or $0.5 \% \mathrm{PF}, 4 \% \mathrm{PF}$, or a mixture of $4 \% \mathrm{PF}, 0.1 \%$ glutaraldehyde (GA), and $0.1 \%$ picric acid (PA) or of $1 \% \mathrm{PF}, 2.5 \% \mathrm{GA}$, and $0.1 \%$ PA for electron microscopy (EM).

Eight more rats were anesthetized with ketamine $(50 \mathrm{mg} / \mathrm{kg})$ and xylazine $(8 \mathrm{mg} / \mathrm{kg})$. Under aseptic conditions, the spinal cord was accessed via laminectomy, the dura was incised unilaterally, and L4-L6 dorsal rootlets were ligated with an 8-0 Prolene filament. These rats were perfused with $4 \%$ PF $2-3$ d after surgery.

To combine immunostaining for AMPAR subunits with labeling for markers for primary afferents, four rats were injected with cholera toxin B subunit (CTB; List Biological Laboratories, Campbell, CA) or isolectin B4 (IB4; Griffonia simplicifolia lectin I; Vector Laboratories, Burlingame, CA). Under anesthesia, the sciatic nerves on both sides were exposed at midthigh level. Two microliters of $1 \%$ CTB or $3 \mu \mathrm{l}$ of $1 \%$ IB4 were injected slowly through a 33 gauge needle using a Hamilton syringe. The rats were allowed to survive for $5 \mathrm{~d}$ after CTB injection and $3 \mathrm{~d}$ after IB4 injection. Sections of spinal cords at level L4-L6 were cut on a Vibratome and stored in cold PB. Section thickness was $50 \mu \mathrm{m}$, except for tissue fixed with 0.5 or $1 \%$ PF $(70 \mu \mathrm{m})$. Dorsal roots and DRGs were cryoprotected with $30 \%$ sucrose and sectioned longitudinally on a freezing microtome at $40 \mu \mathrm{m}$.

For immunostaining with diaminobenzidine (DAB), sections were permeabilized with $50 \%$ ethanol for 30 min (omitted in tissue fixed with 0.5 or $1 \% \mathrm{PF})$, treated with $3 \% \mathrm{H}_{2} \mathrm{O}_{2}$ in $\mathrm{PBS}(0.01 \mathrm{M}, \mathrm{pH} 7.2)$ for $10 \mathrm{~min}$, and then incubated with $10 \%$ normal donkey serum (NDS; Jackson ImmunoResearch, West Grove, PA) in PBS. For material fixed with GA, sections were also pretreated with $1 \% \mathrm{NaBH}_{4}$ for $30 \mathrm{~min}$. Sections were subsequently incubated overnight in the primary antibody in PBS. Four AMPAR antibodies were used. One antibody [glutamate receptor subunit 2/3 (GluR2/3), raised in rabbit, 1:2000; Chemicon, Temecula, CA] recognizes the C-terminus sequences of GluR2 and GluR3 and was characterized by Wenthold et al. (1992). Another antibody (GluR2, raised in rabbit, 1:200; Chemicon) was characterized by Petralia et al. (1997). Of the two other antibodies, one (GluR4, raised in rabbit 1:400; Chemicon) recognizes the C terminus of GluR4 and was characterized by Wenthold et al. (1992), and the other (GluR2/4, 1:2000; Chemicon) was raised in mice (Siegel et al., 1995). The antibodies for GluR2 and for GluR4 selectively recognize the respective subunit (Matsubara et al., 1996; Petralia et al., 1997); anti-GluR2/3 may recognize GluR2/3/4, although it stains predominantly for GluR3 with immunocytochemistry (Petralia et al., 2001; personal communication), and anti-GluR2/4 is not as thoroughly characterized as the others. After incubation with biotinconjugated donkey anti-rabbit or anti-mouse IgG (1:200; Jackson ImmunoResearch) in PBS, sections were incubated with ExtrAvidin peroxidase (1:5000; Sigma, St. Louis, MO) in PBS. Immunoperoxidase was revealed by Ni-DAB. Sections were subsequently mounted on gelatincoated slides and coverslipped with DPX (BDH, Poole, UK).

For immunofluorescence, spinal cord and DRG sections were permeabilized with $50 \%$ ethanol (omitted in tissue fixed with 0.5 or $1 \% \mathrm{PF}$ ), blocked with $10 \%$ NDS, and incubated overnight with primary antibodies (GluR2, 1:100; GluR2/3, 1:500; GluR4, 1:200; and GluR2/4, 1:500). Sections were subsequently incubated with $\mathrm{Cy} 3$-conjugated donkey anti-mouse or anti-rabbit IgG (1:200; Jackson ImmunoResearch) for $3 \mathrm{hr}$, mounted on slides, and coverslipped with Vectashield (Vector Laboratories).

For double immunofluorescence staining, sections were incubated overnight in one of the AMPAR antibodies and either rabbit antisynaptophysin (1:200; Zymed, San Francisco, CA) or mouse antisynaptophysin (1:1000; Sigma). Sections were subsequently blocked in $2 \%$ NDS for $10 \mathrm{~min}$ and incubated in Cy3- or FITC-conjugated donkey anti-rabbit and anti-mouse $\operatorname{IgG}$ (1:200; Jackson ImmunoResearch) for $3 \mathrm{hr}$.

For double-staining of AMPAR and CTB or IB4, sections were incubated with goat anti-choleragenoid antibody (1:3000; List Biologicals) or goat anti-IB4 antibody (1:2000; Vector Laboratories) for $18 \mathrm{hr}$ at $4^{\circ} \mathrm{C}$, stained with Cy3-conjugated donkey anti-goat antibody (1:200; Jackson ImmunoResearch), and subsequently processed for fluorescence staining for AMPAR, as above. For double-staining of GluR4 and calcitonin gene-related peptide (CGRP), tyramide signal amplification
(Renaissance TSA-Direct; DuPont NEN, Boston, MA) was used. After blocking with $10 \%$ NDS, the sections were incubated overnight in the GluR4 antibody $(1: 20,000)$ and subsequently in biotinylated donkey antirabbit IgG (1:200; Jackson ImmunoResearch). After several rinses, the sections were incubated with streptavidin-horseradish peroxidase (1: 200) for $1 \mathrm{hr}$ and then in Cy3-tyramide (1:100) in amplification diluent for $8 \mathrm{~min}$. After rinsing, the sections were immunostained with rabbit anti-CGRP (1:5000; gift from Dr. C. W. Cooper, University of Texas Medical Branch, Galveston, TX) (Fujimura et al., 1985) followed by FITC-conjugated donkey anti-rabbit IgG. Double fluorescence images were acquired with a Leica (Wetzlar, Germany) TCS-NT confocal microscope and saved in TIFF format. Contrast and brightness were adjusted with Photoshop version 6.0 (Adobe Systems, San Jose, CA).

For EM, transverse sections of spinal cord and dorsal roots from six rats were immersed in $30 \%$ sucrose overnight, frozen on dry ice for 15 min, and thawed in PBS to enhance penetration. Sections were also processed for DAB immunostaining as for LM. After rinsing in $\mathrm{PB}$, sections were osmicated $\left(1 \% \mathrm{OsO}_{4}\right.$ in $\left.\mathrm{PB}\right)$, rinsed, immersed in $1 \%$ uranyl acetate in maleate buffer, $\mathrm{pH}$ 6.0, and then dehydrated and wafer-embedded in Epon-Spurr resins (EMS, Fort Washington, PA). Thin sections mounted on copper grids were counterstained with $5 \%$ uranyl acetate and Sato's lead and examined on a Philips Tecnai 12 EM (FEI, Hillsboro, OR).

For quantification, all terminals and their postsynaptic dendrites in eight grid squares of the area with the most immunostaining were tallied if the presynaptic or the postsynaptic element, or both, contained immunostaining. Counts were collected from two grids for each antibody from each of two rats. The percentage of counted profiles in which the immunostaining was presynaptic was compared for the different antibodies.

\section{RESULTS}

Staining for AMPAR subunits in DRG cells is very similar to immunoperoxidase and immunofluorescence staining. With both methods, and under all fixation conditions used here, it is difficult to sort out "positive" from "negative" cell bodies, because, for the most part, these display a gradient of immunoreactivity varying from intense to near background. It is nonetheless possible to observe two features consistently: (1) a large number of DRG cell bodies appear stained with any one of the antibodies used, and (2) small- to medium-sized cells stain more distinctly with either anti-GluR4 or anti-GluR2/4 than with either anti-GluR2 or antiGluR2/3 (Fig. 1). To verify the transport of antigen from the cell bodies to their terminals in the spinal cord, we used two strategies. First, we ligated dorsal roots and observed accumulation of the antigen on the DRG side of the ligature. Of the four antibodies under study, anti-GluR2 showed the least apparent accumulation (Fig. 2A), anti-GluR2/3 and anti-GluR2/4 showed the most conspicuous accumulation (Fig. $2 B, D$ ), and anti-GluR4 showed accumulation between the two extremes (Fig. $2 C$ ). Second, we assessed, by EM, the presence of immunoreactive fibers in transverse sections of untreated dorsal roots. The results from this material varied somewhat in quantitative terms with all fixatives used but were consistent enough to allow some unequivocal generalizations and to rule out the possibility that the selectivity of the staining pattern may be related to different fixation protocols. Staining for GluR2 is present only faintly and in occasional unmyelinated fibers. Unmyelinated fibers immunopositive for GluR2 are also sparsely present in the superficial laminas of the dorsal horn (Fig. 3A). Numerous dorsal root fibers, primarily myelinated, were immunostained with anti-GluR2/3 (Fig. 3B) and, primarily unmyelinated, with anti-GluR4 (Fig. $3 C$ ) or antiGluR2/4 (Fig. 3D).

Immunostaining for GluR2, GluR2/3, and GluR2/4 predominated in superficial laminas of the dorsal horn, particularly lamina II and the dorsal portion of lamina III (Fig. $4 A, B, D$ ). Numerous cell bodies were stained in these laminas, interspersed in a dense 

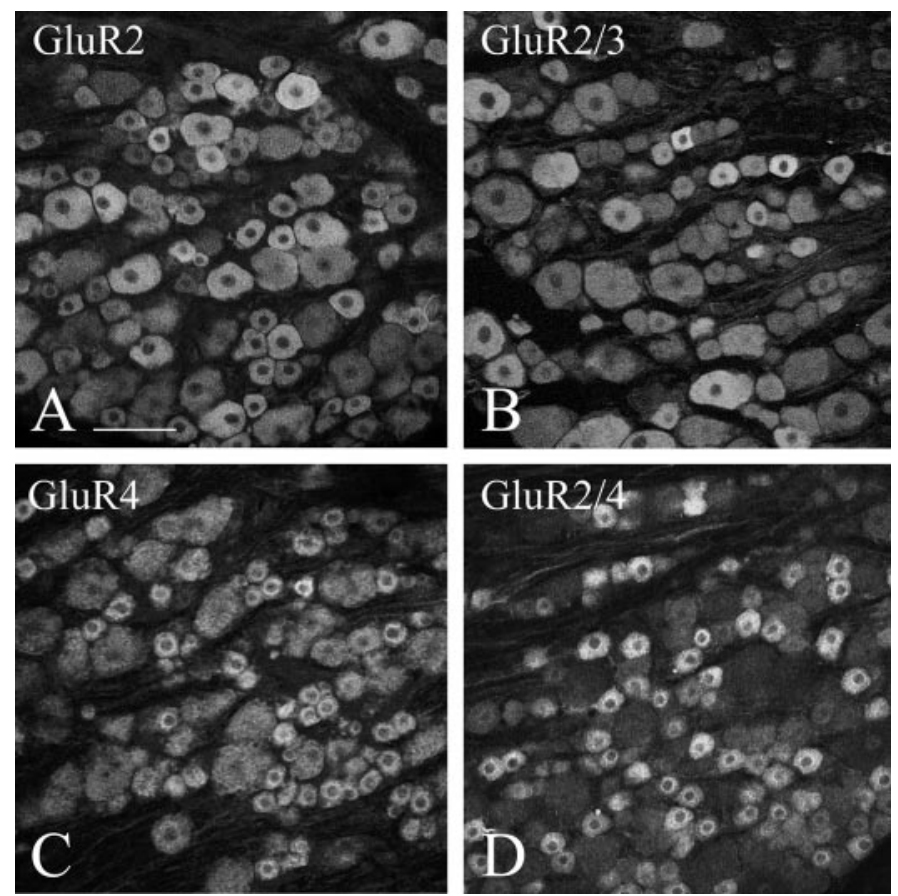

Figure 1. Immunofluorescent staining in rat DRG at L4. Staining for GluR2 $(A)$ and GluR2/3 $(B)$ is seldom pronounced and does not appear to be selective for either small or large cells. Staining for GluR4 $(C)$ and GluR2/4 $(D)$ is more selective than staining for GluR2 or GluR2/3 for small and medium cells. Scale bar, $100 \mu \mathrm{m}$.

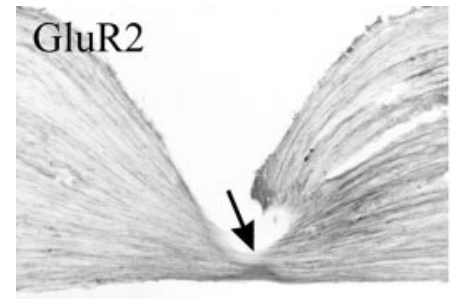

A

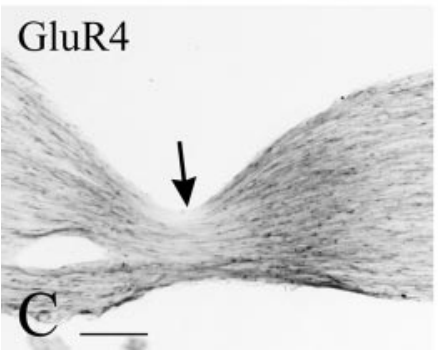

\section{GluR2/3}
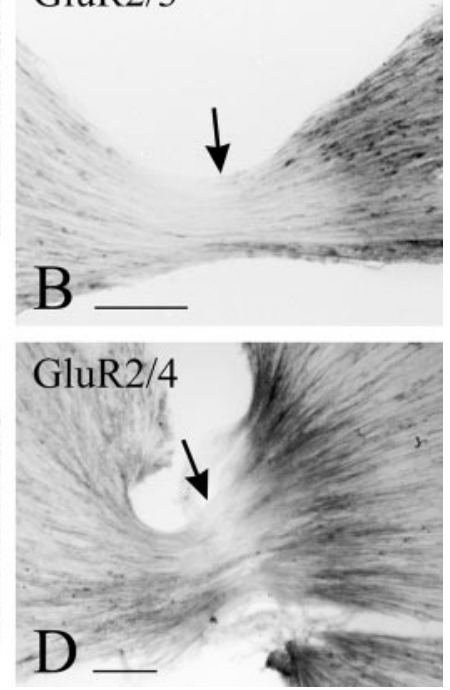

Figure 2. Immunoperoxidase staining of ligated L4 dorsal roots. Accumulation of immunostain on the side of DRG (right) is most evident for GluR2/3 $(B)$ and GluR2/4 $(D)$, weak for GluR2 $(A)$, and intermediate for GluR4 (C). Arrows point to the ligature site. Scale bars, $100 \mu \mathrm{m}$.

immunopositive neuropil. Anti-GluR4 yielded the faintest staining in these laminas, compared with the other antibodies, with hardly any perikaryal staining (Fig. 4C). Most of the observed staining was somatodendritic and thus likely to be postsynaptic, but we explored the extent to which some of the staining could be in terminals by simultaneous staining with the presynaptic marker synaptophysin. Numerous double-stained puncta were observed in this material, particularly when anti-GluR2/4 was used, but
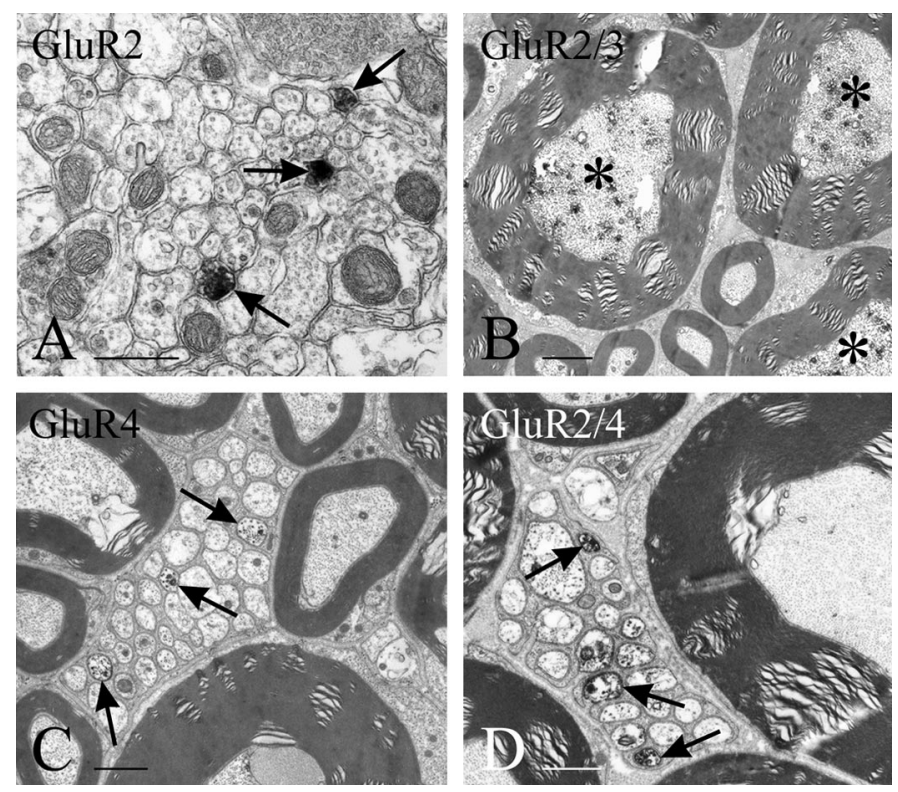

Figure 3. EM immunostaining of cross sections through spinal lamina II at L4 (with anti-GluR2, $A$ ) and L4 dorsal roots $(B-D)$; staining is detectable as dark patches of DAB product especially in myelinated fibers with anti-GluR2/3 (B, asterisks) and in unmyelinated primary afferent fibers with GluR4 or GluR2/4 $(C, D$, arrows). Immunostained unmyelinated fibers are indicated by arrows. Scale bars: $A, 0.5 \mu \mathrm{m} ; B, 2 \mu \mathrm{m} ; C, D$, $1 \mu \mathrm{m}$.

none when anti-GluR2 was used. Puncta double-stained for synaptophysin and GluR2/4 or GluR4 predominated in laminas I and II. Puncta double-stained for synaptophysin and GluR2/3 predominated in laminas III and IV and were detectable only in material fixed with 0.5 or $1 \% \mathrm{PF}$.

We subsequently double-stained for AMPAR subunits and for each of three selective markers of primary afferents: (1) CTB to label terminals of myelinated afferents, (2) IB4 to label terminals of nonpeptidergic unmyelinated afferents, and (3) CGRP to label terminals of peptidergic unmyelinated afferents. With this double-labeling strategy, we obtained virtually no colocalization of staining for any of the AMPAR subunits tested with CGRP. Conversely, we observed a clear prevalence of colocalization of GluR4 or GluR2/4 with IB4 (Fig. 4E) and of GluR2/3 with CTB (Fig. $4 F$ ) and no double-staining of GluR2 with either marker.

The most definite evidence for the presence of presynaptic AMPAR subunits in terminals in superficial laminas of the dorsal horn was obtained by EM (Fig. 5). Although comparable data were obtained for anti-GluR4, anti-GluR2/4, or anti-GluR2 regardless of whether $0.5 \%$ or $4 \% \mathrm{PF}$ or $4 \% \mathrm{PF}$ and $0.1 \% \mathrm{GA}$, with or without PA, was used as perfusion fixative, detection of terminals stained for GluR2/3 required the use of concentrations of $\mathrm{PF} \leq 1 \%$ (without GA). Immunostaining for GluR2/3, conversely, was present in cell bodies and dendrites in material fixed with either mixed aldehydes or $0.5 \% \mathrm{PF}$.

In close agreement with the LM results and with the observations from dorsal roots, GluR2-immunopositive terminals were very sparse throughout the superficial laminas of the dorsal horn; however, GluR2 was readily detectable in cell bodies and postsynaptic dendrites (Fig. 5A). In contrast, GluR4-immunopositive (Figs. $5 B, E, 6 C$ ) and GluR2/4-immunopositive (Figs. 5C,F, 6D) terminals were numerous in lamina II, and GluR2/3-immunopositive terminals were detectable in laminas III and IV (Figs. 5D, 

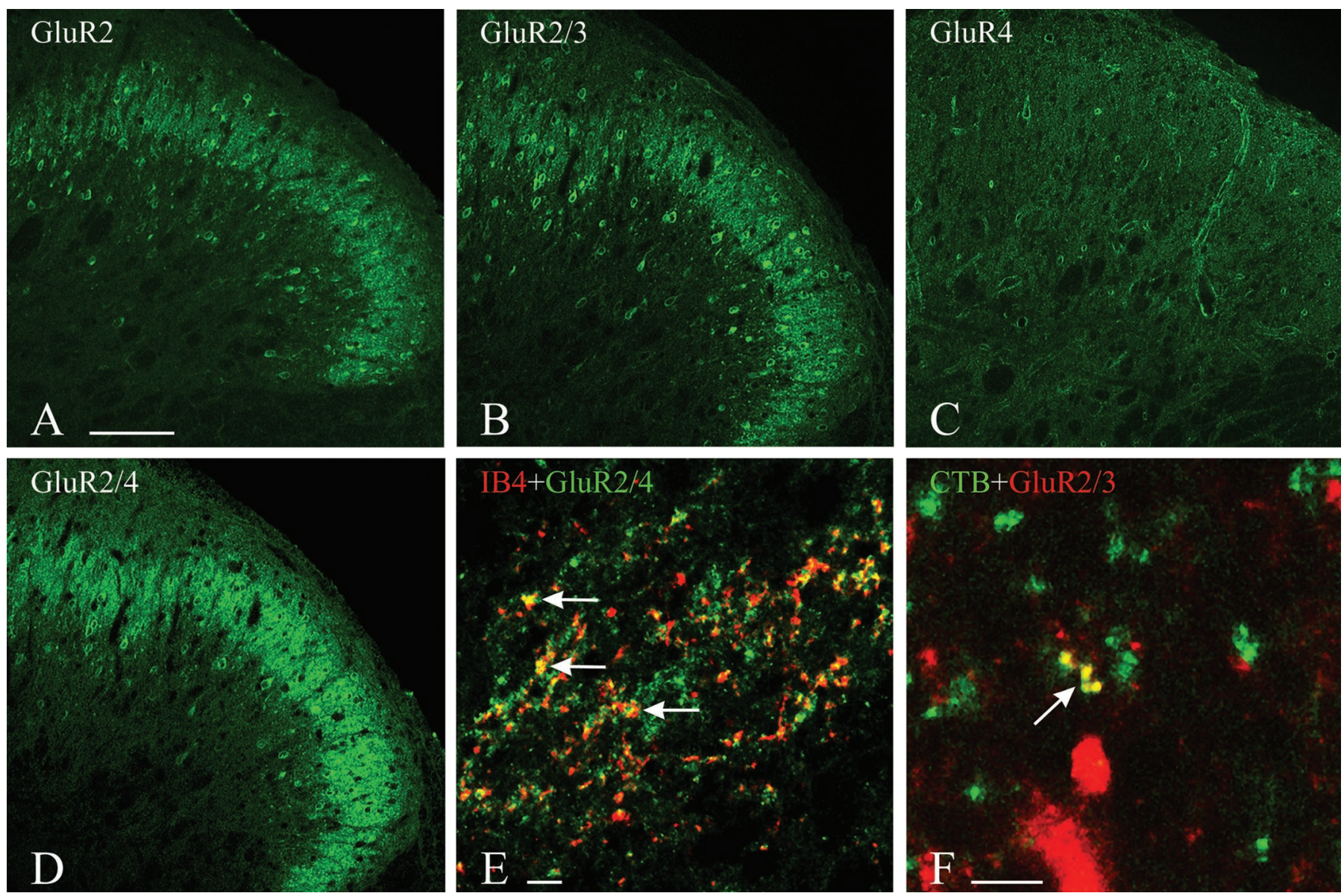

Figure 4. $A-D$, Immunofluorescent staining in rat dorsal horn at L4. The staining for GluR2 $(A)$, GluR2/3 $(B)$, and GluR2/4 $(D)$ is in neuronal perikarya and dense puncta, primarily in lamina II; the staining for GluR4 $(C)$ is punctate and more diffuse. $E$, $F$, Double-staining for AMPAR subunits and tracers. $E$, Staining for GluR2/4 has been combined with IB4 immunofluorescence to detect presynaptic labeling of presumed unmyelinated fiber terminals in lamina II. F, Staining for GluR2/3 has been combined with CTB immunofluorescence to detect presynaptic labeling of presumed myelinated fiber terminals in lamina III. Colocalization is indicated by arrows $(E, F)$. Scale bars, $100 \mu \mathrm{m}$.

$6 B)$. Within stained terminals, the immunoproduct tended to be located peripherally, i.e., along the plasma membrane (Figs. $5 B-F, 6 A-D)$. Only occasionally was presynaptic staining observed with the GluR4 and GluR2/4 antibodies in terminals that contained dense-core vesicles.

Quantitative data were gathered from material with the highest concentration of fixative compatible with detection of presynaptic staining and are shown in Table 1. The density of GluR2/3immunopositive terminals (25-30\%) is intermediate between that of GluR2- $(5 \%)$ and GluR4- or GluR2/4-immunopositive terminals $(\sim 70 \%)$. In material stained with anti-GluR4 or antiGluR2/4, more synapses displayed immunoproduct presynaptically than postsynaptically, whereas with anti-GluR2/3, most of the immunostaining occurred in postsynaptic dendrites.

The majority of GluR2/3-immunopositive terminals are of one of two types. One is large, irregularly shaped, forms clearly asymmetric synapses with more than one profile in the plane of the section, and contains numerous round vesicles (some coated), mitochondria, and neurofilaments (Fig. 5D). This morphology has been associated with terminals of primary afferent endings in laminas III and IV (Valtschanoff et al., 1994). Terminals of the other type are smaller, contain flattened vesicles, and establish single symmetric synapses onto small dendritic profiles (Fig. 6B). This morphology suggests that the terminals arise from intrinsic, probably GABAergic, neurons.
Most terminals in lamina II that are immunopositive for either GluR4 or GluR2/4 are identifiable as endings of primary afferent fibers, because of their characteristic morphology (i.e., large, vesicle-filled, scalloped), establishing more than one asymmetrical synapse in the plane of the section, and at the center of a synaptic glomerulus of either type 1 or type 2 , according to the classification of Ribeiro-da-Silva and Coimbra (1982). Endings at the center of type 1 glomeruli (Fig. 5B,C) are presumed to originate from unmyelinated fibers and are more frequently immunopositive for GluR4 or GluR2/4 than are primary afferent endings of type 2 glomeruli (Fig. $5 E, F$ ). These endings have a more regular contour than endings in type 1 glomeruli, have light axoplasm, and contain uniform round vesicles and numerous mitochondria. They are presumed to originate from A $\delta$ fibers. Immunostained terminals for either GluR4 or GluR2/4 can also be smaller, contain flattened vesicles, and establish a single symmetrical synapse. Terminals with these morphological features are likely to be from GABAergic neurons and are occasionally presynaptic to primary afferent terminals (Fig. 6D).

\section{DISCUSSION}

Systematic microscopic documentation of PIGRs in central terminals of primary afferents has been made possible recently by the use of reliable methods for simultaneous identification (by LM) of terminals and immunostaining for kainate (Hwang et al., 

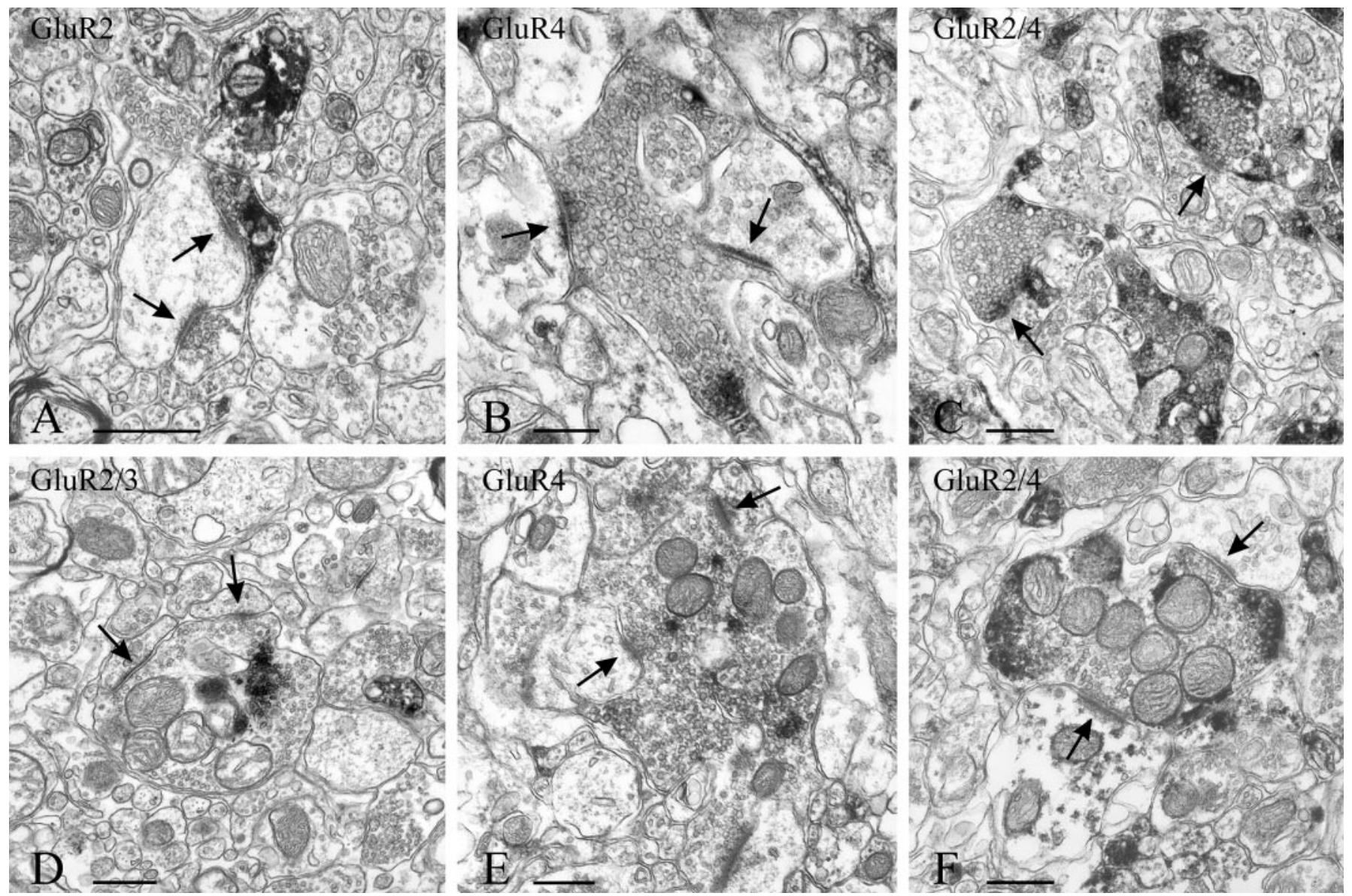

Figure 5. EM immunostaining of terminals identifiable for their morphology as endings of primary afferents. Staining is detectable as dark patches of DAB in terminals (synapses are indicated by arrows). Immunoreactivity for GluR2 $(A)$ is primarily postsynaptic and seen only rarely in terminals. The preservation of the tissue for visualization of immunoreactivity for GluR2/3 $(D)$ is affected by the use of a low concentration of PF in the fixative. Central terminals of both type $1(B, C)$ and type $2(E, F)$ glomeruli, characteristic of lamina II, are immunostained with GluR4 or GluR2/4. Scale bars, $0.5 \mu \mathrm{m}$.

2001a,b) and NMDA receptors (our unpublished observations), and by refinement in EM techniques (Liu et al., 1994; Ginsberg et al., 1995; Peng et al., 1995; Siegel et al., 1995; Ye and Westlund, 1996).

In the superficial laminas of the spinal cord, Liu et al. (1994) reported that in approximately one-third of the synapses immunolabeled with an NMDA antibody, the immunolabeling was presynaptic. Ye and Westlund (1996), conversely, reported occasional immunolabeling for NMDA or GluR2/3 in synaptic terminals contacting identified spinothalamic cells. In both reports, mixed aldehydes were used, and this might have resulted in an underestimate of the frequency of expression of PIGRs in the spinal cord. We reported previously that kainate receptors can be presynaptic in a sizeable fraction of primary afferent terminals in the superficial laminas of the spinal dorsal horn (Hwang et al., 2001a) and in the dorsal column nuclei (Hwang et al., 2001b) and noted that whereas immunostaining for kainate receptors in cell bodies and dorsal root fibers was not affected significantly by fixation, immunostaining for PIGRs in central terminals required more diluted fixation than used routinely. Alternative strategies to preserve the immunogenicity of PIGRs and the reason that led us to choose fixation with only PF or diluted PF are discussed by Hwang et al. (2001a).

In early reports on AMPAR subunits in DRG of adult rats, numerous neurons were immunostained for GluR2/3 (Sato et al.,
1993; Tachibana et al., 1994). The same authors observed only sparse immunostaining for GluR4 in DRG. In the work by Tachibana et al. (1994), immunostaining for GluR4 was assigned to satellite cells; however, some of the immunostained cells in their illustrations are similar in shape and size to small DRG neurons immunopositive for the same antigen in the present study. GluR4immunopositive small DRG neurons have also been reported by Chambille and Rampin (2002). Recent work has suggested that AMPAR may be functional not in the cell body of DRG neurons but rather at the synapses between terminals of these cells and dorsal horn neurons (Lee et al., 2002). Considering this and the transport of the receptors over long distances peripherally and centrally, it is not surprising that expression of AMPAR subunits in DRG cells displays a gradient of intensities that prevents determination of proportions of neurons that are stained for a given subunit. Although we noticed immunostaining for GluR2 in DRG cells, GluR2 is in very few dorsal root fibers and in only 5\% of the synapses we counted. A survey of sections stained for GluR1 suggests results very similar to those obtained with GluR2 (our unpublished results). A possible interpretation is that some AMPAR subunits are transported only, or primarily, peripherally. Notwithstanding these considerations, large DRG neurons are immunostained predominantly by anti-GluR2/3, and smaller cells are immunostained predominantly by anti-GluR 4 or antiGluR2/4. These two major morphological classes of DRG cells 

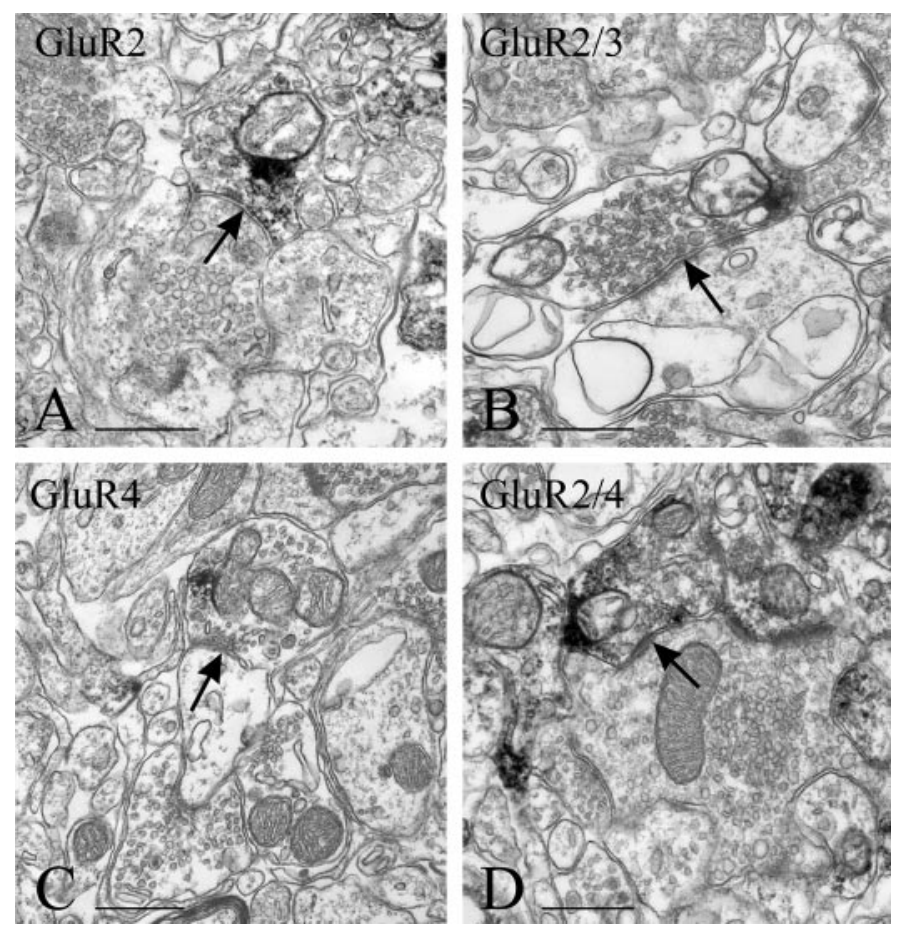

Figure 6. EM immunostaining of presumed GABAergic terminals ( $a r$ rows). Terminals of this type are only occasionally stained for GluR2 $(A)$ and more frequently for GluR2/3 (B) than for either GluR4 $(C)$ or GluR2/4 $(D)$. Immunoreactive terminals with these morphological characteristics can be seen apposed to primary afferent terminals in lamina II $(A, D)$. Scale bars, $0.5 \mu \mathrm{m}$.

are usually associated with myelinated and unmyelinated afferent fibers, respectively (Willis and Coggeshall, 1991). In transverse sections of dorsal roots, we not only verified by EM the central transport of AMPAR subunits but also confirmed the preferential immunostaining for GluR2/3 in myelinated fibers and for GluR4 or GluR2/4 in unmyelinated fibers.

Because the simultaneous staining of AMPAR subunits and a generic marker for terminals (i.e., synaptophysin) showed many double-stained puncta in the dorsal horn, we proceeded to the identification of the types of afferents that express them. CTB is a marker for myelinated fibers that terminate in laminas I and III through IX (Woodbury et al., 2000). In agreement with the immunostaining in DRGs and in dorsal roots, primary afferents that transport CTB are immunopositive for GluR2/3. Because of their laminar termination in laminas III and IV, CTB-labeled terminals immunopositive for GluR2/3 could be endings of A $\delta$ fibers, possibly mediating noxious mechanical and thermal stimuli (Caterina and Julius, 2001), although many may also be endings of low-threshold mechanoreceptors, which also terminate in this lamina (Willis and Coggeshall, 1991). The apparently limited number of such terminals under LM may reflect a true sparsity of primary afferent terminals expressing GluR2/3. However, several considerations suggest that our LM approach did not reveal the entire population of these terminals. First, the density of immunostained terminals increases with progressively more diluted fixatives. Thus, it cannot be excluded that even with the fixation used here, immunogenicity of presynaptic GluR2/3 receptors was diminished sufficiently to impair detection by LM. Second, numerous dorsal root fibers are immunopositive for GluR2/3. Third, with EM, immunoreactivity in these terminals, as in most other terminals expressing other AMPAR subunits, is in small, frag- mented patches around the periphery of the terminal, too small to be detected by LM. The apparent discrepancy between the small number of GluR2/3-immunopositive terminals that are also labeled by CTB and the quantitative data obtained with EM is explained by the large proportion of terminals immunopositive for GluR2/3 with morphological characteristics of GABAergic terminals. We interpret the staining for GluR2/3 as suggestive of the expression of GluR3 in terminals of intrinsic, perhaps inhibitory interneurons, as well as in CTB-labeled terminals, because we detected only a small percentage of presynaptic staining with the GluR2 antibody.

Unmyelinated (slowly conducting, C) fibers may subserve different sensory modalities, but for the most part, they respond to intense stimuli activating polymodal nociceptors (Hunt and Mantyh, 2001). Although some controversy exists on the sharpness of the distinction, unmyelinated fibers can be peptidergic (CGRPpositive) and nonpeptidergic (IB4-positive). Their terminals predominate in the outer and inner parts of lamina II, respectively. Although the functional characterization of these two types of fibers is not yet complete, both may mediate nociceptive input but differ, at the same time, in several respects (Belyantseva and Lewin, 1999; Stucky and Lewin, 1999; Vulchanova et al., 2001). Our results suggest that AMPAR subunits are expressed in a large fraction of the nonpeptidergic group of afferents, primarily in lamina II terminals that are at the center of glomeruli of type 1 , presumed to be at the end of unmyelinated fibers (Ribeiroda-Silva and Coimbra, 1982). We interpret the staining for GluR4 or GluR2/4 as suggestive of the expression of GluR4 in IB4labeled terminals because of the small percentage of presynaptic labeling with the GluR2 antibody. Fixation constraints prevented us from testing, by double-labeling, the origin of GluR4immunopositive terminals in material prepared for EM. However, their predominance at the center of glomeruli in lamina II suggests that the majority are endings of primary afferents. Our data also suggest that some intrinsic terminals may express GluR4. As for GluR2/3-immunopositive terminals, direct testing of whether GluR4-immunopositive terminals are GABAergic requires weaker fixative than is compatible with detection of GABA. Systematic double-staining strategies are also needed to determine the extent to which different AMPAR subunits coexist in the same terminal and/or with kainate and NMDA receptor subunits.

By showing that primary afferent terminals in the dorsal horn express not only NMDA (Liu et al., 1994) and metabotropic (Jia et al., 1999) or kainate (Hwang et al., 2001a) receptors but also AMPAR subunits, the present results establish that most glutamate receptor subunits synthesized in DRG neurons are transported centrally as well as peripherally (Coggeshall and Carlton, 1998). The demonstration of selective expression of AMPAR subunits in terminals of the dorsal horn underscores the functional specificity of these afferents, although their functional role remains to be elucidated. The sparseness of GluR2, the subunit that limits the $\mathrm{Ca}^{2+}$ permeability of the AMPAR (Jonas and Burnashev, 1995), supports the presynaptic modulation of neurotransmitter release in terminals of the dorsal horn via depolarization of the terminal and $\mathrm{Ca}^{2+}$ entry through the ligand-gated ion channel (Khack and Henderson, 2000). Presynaptic AMPARs may play a role in primary afferent depolarization, as suggested recently by Lee et al. (2002). They are unlikely to regulate the release of peptides, as suggested for presynaptic NMDA (Liu et al., 1997), but may play a role in nociception, particularly in certain states of chronic pain, because they are expressed selec- 
Table 1. Quantitative evaluation of presynaptic expression of AMPAR subunits in dorsal horn

\begin{tabular}{|c|c|c|c|c|c|c|}
\hline Antibody & Animal & Fixative & Laminas & $\begin{array}{l}\text { Presynaptic } \\
\text { staining }\end{array}$ & Synapses & Percentage \\
\hline \multirow[t]{4}{*}{ GluR2 } & \multirow[t]{2}{*}{ R2411 } & \multirow[t]{2}{*}{$4 \% \mathrm{PF}$} & \multirow[t]{2}{*}{ I-III } & 5 & 102 & 4.9 \\
\hline & & & & 4 & 92 & 4.3 \\
\hline & \multirow[t]{2}{*}{$\mathrm{R} 2412$} & \multirow[t]{2}{*}{$4 \% \mathrm{PF}$} & \multirow[t]{2}{*}{ I-III } & 5 & 93 & 5.4 \\
\hline & & & & 6 & 123 & 4.9 \\
\hline Total & & & & 20 & 410 & 4.9 \\
\hline \multirow[t]{4}{*}{ GluR2/3 } & \multirow[t]{2}{*}{ R2409 } & \multirow[t]{2}{*}{$0.5 \% \mathrm{PF}$} & \multirow[t]{2}{*}{ III-IV } & 28 & 105 & 26.7 \\
\hline & & & & 22 & 81 & 27.2 \\
\hline & \multirow[t]{2}{*}{$\mathrm{R} 2410$} & \multirow[t]{2}{*}{$0.5 \% \mathrm{PF}$} & \multirow[t]{2}{*}{ III-IV } & 24 & 103 & 23.3 \\
\hline & & & & 19 & 98 & 19.4 \\
\hline Total & & & & 93 & 387 & 24.2 \\
\hline \multirow[t]{4}{*}{ GluR4 } & \multirow[t]{2}{*}{ R2399 } & \multirow[t]{2}{*}{$4 \% \mathrm{PF}+0.1 \% \mathrm{GA}+0.1 \% \mathrm{PA}$} & \multirow[t]{2}{*}{ I-III } & 43 & 58 & 74.1 \\
\hline & & & & 43 & 55 & 78.2 \\
\hline & \multirow[t]{2}{*}{$\mathrm{R} 2411$} & \multirow[t]{2}{*}{$4 \% \mathrm{PF}$} & \multirow[t]{2}{*}{ I-III } & 39 & 53 & 73.6 \\
\hline & & & & 41 & 56 & 73.2 \\
\hline Total & & & & 166 & 222 & 74.8 \\
\hline \multirow[t]{4}{*}{ GluR2/4 } & \multirow[t]{2}{*}{$\mathrm{R} 2411$} & \multirow[t]{2}{*}{$4 \% \mathrm{PF}$} & \multirow[t]{2}{*}{ I-III } & 73 & 96 & 76.0 \\
\hline & & & & 73 & 106 & 68.9 \\
\hline & \multirow[t]{2}{*}{$\mathrm{R} 2412$} & \multirow[t]{2}{*}{$4 \% \mathrm{PF}$} & \multirow[t]{2}{*}{ I-III } & 74 & 99 & 74.7 \\
\hline & & & & 72 & 98 & 73.5 \\
\hline Total & & & & 292 & 399 & 73.3 \\
\hline
\end{tabular}

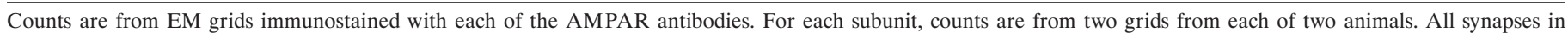

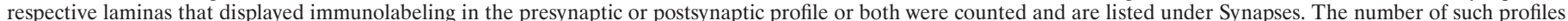

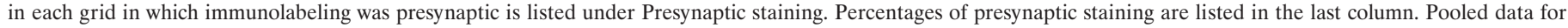
each subunit are shown in bold italics. PF, Paraformaldehyde; GA, glutaraldehyde; PA, picric acid.

tively in nonpeptidergic C fibers (Hunt and Mantyh, 2001). They may act as both autoreceptors in primary afferent terminals and as heteroreceptors if confirmed directly in GABAergic or glycineergic terminals. In addition, the hypothesis that AMPARs may be activated by release of glutamate by glial processes around synaptic terminals (Haydon, 2001) is a promising lead for future investigation of their functional role.

\section{REFERENCES}

Agrawal SG, Evans RH (1986) The primary afferent depolarizing action of kainate in the rat. Br J Pharmacol 87:345-355.

Ault B, Hildebrand LM (1993) Activation of nociceptive reflexes by peripheral kainate receptors. J Pharmacol Exp Ther 265:927-932.

Belyantseva IA, Lewin GR (1999) Stability and plasticity of primary afferent projections following nerve regeneration and central degeneration. Eur J Neurosci 11:457-468.

Bureau I, Mulle C (1998) Potentiation of GABAergic synaptic transmission by AMPA receptors in mouse cerebellar stellate cells: changes during development. J Physiol (Lond) 509:817-831.

Caicedo A, Jafri MS, Roper SD (2000) In situ $\mathrm{Ca}^{2+}$ imaging reveals neurotransmitter receptors for glutamate in taste receptor cells. J Neurosci 20:7978-7985.

Carlton SM, Coggeshall RE (1999) Inflammation-induced changes in peripheral glutamate receptor populations. Brain Res 820:63-70.

Carlton SM, Hargett GL, Coggeshall RE (1995) Localization and activation of glutamate receptors in unmyelinated axons of rat glabrous skin. Neurosci Lett 197:25-28.

Carlton SM, Hargett GL, Coggeshall RE (1998) Plasticity in alphaamino-3-hydroxy-5-methyl-4-isoxazolepropionic acid receptor subunits in the rat dorsal horn following deafferentation. Neurosci Lett 242:21-24.

Casado M, Dieudonne S, Ascher P (2000) Presynaptic N-methyl-Daspartate receptors at the parallel fiber-Purkinje cell synapse. Proc Natl Acad Sci USA 97:11593-11597.

Caterina MJ, Julius D (2001) The vanilloid receptor: a molecular gateway to the pain pathway. Annu Rev Neurosci 24:487-517.

Chambille I, Rampin O (2002) AMPA glutamatergic receptorimmunoreactive subunits are expressed in lumbosacral neurons of the spinal cord and neurons of the dorsal root and pelvic ganglia controlling pelvic functions in the rat. Brain Res 933:66-80.

Chittajallu R, Vignes M, Dev KK, Barnes JM, Collingridge GL, Henley
JM (1996) Regulation of glutamate release by presynaptic kainate receptors in the hippocampus. Nature 379:78-81.

Coggeshall RE, Carlton SM (1998) Ultrastructural analysis of NMDA, AMPA, and kainate receptors on unmyelinated and myelinated axons in the periphery. J Comp Neurol 391:78-86.

Cossart R, Tyzio R, Dinocourt C, Esclapez M, Hirsch JC, Ben-Ari Y, Bernard C (2001) Presynaptic kainate receptors that enhance the release of GABA on CA1 hippocampal interneurons. Neuron 29:497-508.

Davidson EM, Carlton SM (1998) Intraplantar injection of dextrophan, ketamine or memantine attenuates formalin-induced behaviors. Brain Res 785:136-142.

Davies J, Evans RH, Francis AA, Watkins JC (1979) Excitatory amino acid receptors and synaptic excitation in the mammalian central nervous system. J Physiol (Lond) 75:641-654.

Du J, Koltzenburg M, Carlton SM (2001) Glutamate-induced excitation and sensitization of nociceptors in rat glabrous skin. Pain 89:187-198.

Fabian-Fine R, Volknandt W, Fine A, Stewart MG (2000) Agedependent pre- and postsynaptic distribution of AMPA receptors at synapses in CA3 stratum radiatum of hippocampal slice cultures compared with intact brain. Eur J Neurosci 12:3687-3700.

Friedman D, Strowbridge BW (2000) Functional role of NMDA autoreceptors in olfactory mitral cells. J Neurophysiol 84:39-50.

Fujimura M, Hancock MB, Cooper CW, Reumont K, Greely GH, Thompson JC (1985) Immunocytochemical localization of calcitonin gene-related peptide in pancreatic islet cells of the rat. Gastroenterology 88:1390.

Ginsberg SD, Price DL, Blackstone CD, Huganir RL, Martin LJ (1995) The AMPA glutamate receptor GluR3 is enriched in oxytocinergic magnocellular neurons and is localized at synapses. Neuroscience 65:563-575

Glitsch M, Marty A (1999) Presynaptic effects of NMDA in cerebellar Purkinje cells and interneurons. J Neurosci 19:511-519.

Haydon PG (2001) Glia: listening and talking to the synapse. Nat Rev Neurosci 2:185-193.

Huettner JE (1990) Glutamate receptor channels in rat DRG neurons: activation by kainate and quisqualate and blockade of desensitization by Con A. Neuron 5:255-266.

Hunt SP, Mantyh PW (2001) The molecular dynamics of pain control. Nat Rev Neurosci 2:83-91.

Hwang SJ, Pagliardini S, Rustioni A, Valtschanoff JG (2001a) Presynaptic kainate receptors in primary afferents to the superficial laminae of the rat spinal cord. J Comp Neurol 436:275-289.

Hwang SJ, Rustioni A, Valtschanoff JG (2001b) Kainate receptors in primary afferents to the rat gracile nucleus. Neurosci Lett 312:137-140. 
Jia H, Rustioni A, Valtschanoff JG (1999) Metabotropic glutamate receptors in superficial laminae of the rat dorsal horn. J Comp Neurol 410:627-642.

Jonas P, Burnashev N (1995) Molecular mechanisms controlling calcium entry through AMPA-type glutamate receptor channels. Neuron 15:987-990.

Kerchner GA, Wilding TJ, Li P, Zhuo M, Huettner JE (2001) Presynaptic kainate receptors regulate spinal sensory transmission. J Neurosci 21:59-66.

Khack BS, Henderson G (2000) Modulation of fast synaptic transmission by presynaptic ligand-gated cation channels. J Auton Nerv Syst $81: 110-121$.

Kinkelin I, Bröcker EB, Koltzenburg M, Carlton SM (2000) Localization of ionotropic glutamate receptors in peripheral axons of human skin. Neurosci Lett 283:149-152.

Lawand NB, Willis WD, Westlund KN (1997) Excitatory amino acid receptor involvement in peripheral nociceptive transmission in rats. Eur J Pharmacol 324:169-177.

Lee CJ, Engelman HS, MacDermott AB (1999) Activation of kainate receptors on rat sensory neurons evokes action potential firing and may modulate transmitter release. Ann NY Acad Sci 868:546-549.

Lee CJ, Bardoni R, Tong CK, Engelman HS, Joseph DJ, MacDermott AB (2002) Functional expression of AMPA receptors on central terminals of rat dorsal root ganglion neurons and presynaptic inhibition of glutamate release. Neuron 35:135-146.

Liu H, Wang H, Sheng M, Jan LY, Jan YN, Basbaum AI (1994) Evidence for presynaptic $N$-methyl-D-aspartate autoreceptors in the spinal cord dorsal horn. Proc Natl Acad Sci USA 91:8383-8387.

Liu H, Mantyh PW, Basbaum AI (1997) NMDA-receptor regulation of substance $\mathrm{P}$ release from primary afferent nociceptors. Nature 386:721-724

Marvizón JCG, McRoberts JA, Ennes HS, Song B, Wang X, Jinton L, Corneliussen B, Mayer EA (2002) Two N-methyl-D-aspartate receptors in rat dorsal root ganglia with different subunit composition and localization. J Comp Neurol 446:325-341.

Matsubara A, Laake JH, Davanger S, Usami S, Ottersen OP (1996) Organization of AMPA receptor subunits at a glutamate synapse: a quantitative immunogold analysis of hair cell synapses in the rat organ of Corti. J Neurosci 16:4457-4467.

McDermott AB, Role LW, Siegelbaum SA (1999) Presynaptic ionotropic receptors and the control of transmitter release. Annu Rev Neurosci 22:443-485.

Meir A, Ginsburg S, Butkevich A, Kachalsky SG, Kaiserman I, Ahdut R, Demirgoren S, Rahamimoff R (1999) Ion channels in presynaptic nerve terminals and control of transmitter release. Physiol Rev 79:1019-1088

Paquet M, Smith Y (2000) Presynaptic NMDA receptor subunit immunoreactivity in GABAergic terminals in rat brain. J Comp Neurol 423:330-347.

Partin KM, Patneau DK, Winters CA, Mayer ML, Buonanno A (1993) Selective modulation of desensitization at AMPA versus kainate receptors by cyclothiazide and concanavalin A. Neuron 11:1069-1082.

Patel DR, Young AM, Croucher MJ (2001) Presynaptic $\alpha$-amino-3hydroxy-5-methyl-4-isoxazole propionate receptor-mediated stimulation of glutamate and GABA release in the rat striatum in vivo: a dual-label microdialysis study. Neuroscience 102:101-111.

Peng Y-W, Blackstone CD, Huganir RL, Yau K-W (1995) Distribution of glutamate receptor subtypes in the vertebrate retina. Neuroscience 66:483-497.

Petralia RS, Yokotani N, Wenthold RJ (1994) Light and electron microscope distribution of the NMDA receptor subunit NMDAR1 in the rat nervous system using a selective anti-peptide antibody. J Neurosci 14:667-696.

Petralia RS, Wang Y-X, Mayat E, Wenthold RJ (1997) Glutamate receptor subunit 2-selective antibody shows a differential distribution of calcium-impermeable AMPA receptors among populations of neurons. J Comp Neurol 385:456-476.

Petralia RS, Sans M, Vissel B, Wang Y-X, Royle GA, Noben-Trauth K,
Heinemann SF, Wenthold RJ (2001) Distribution of glutamate receptors in mice lacking the AMPA receptor subunit, GluR2. Soc Neurosci Abstr 27:481.7.

Picaud S, Larsson HP, Wellis DP, Lecar H, Werblin F (1995) Cone photoreceptors respond to their own glutamate release in the tiger salamander. Proc Natl Acad Sci USA 92:9417-9421.

Pittaluga A, Bonfanti A, Raiteri M (1997) Differential desensitization of ionotropic non-NMDA receptors having distinct neuronal location and function. Naunyn Schmiedebergs Arch Pharmacol 356:29-38.

Raiteri M, Garrone B, Pittaluga A (1992) $N$-methyl-D-aspartic acid (NMDA) and non-NMDA receptors regulating hippocampal norepinephrine release. II. Evidence for functional cooperation and for coexistence on the same axon terminal. J Pharmacol Exp Ther 260:238-242.

Ribeiro-da-Silva A, Coimbra A (1982) Two types of synaptic glomeruli and their distribution in laminae I-III of the rat spinal cord. J Comp Neurol 209:176-186.

Satake S, Saitow F, Yamada J, Konishi S (2000) Synaptic activation of AMPA receptors inhibits GABA release from cerebellar interneurons. Nat Neurosci 3:551-558.

Sato K, Kiyama H, Park HT, Tohyama M (1993) AMPA, KA and NMDA receptors are expressed in the rat DRG neurones. NeuroReport 4:1263-1265.

Schmitz D, Mellor J, Nicoll RA (2001) Presynaptic kainate receptor mediation of frequency facilitation at hippocampal mossy fiber synapses. Science 291:1972-1976.

Shigemoto R, Ohishi H, Nakanishi S, Mizuno N (1992) Expression of the mRNA for the rat NMDA receptor (NMDAR1) in the sensory and autonomic ganglion neurons. Neurosci Lett 144:229-232.

Siegel SJ, Janssen WG, Tullai JW, Rogers SW, Moran T, Heinemann SF, Morrison JH (1995) Distribution of the excitatory amino acid receptor subunits GluR2(4) in monkey hippocampus and colocalization with subunits GluR5-7 and NMDAR1. J Neurosci 15:2707-2719.

Smirnova T, Laroche S, Errington ML, Hicks AA, Bliss TV, Mallet J (1993) Transsynaptic expression of a presynaptic glutamate receptor during hippocampal long-term potentiation. Science 262:433-436.

Stucky CL, Lewin GR (1999) Isolectin $\mathrm{B}_{4}$-positive and -negative nociceptors are functionally distinct. J Neurosci 19:6497-6505.

Tachibana M, Wenthold RJ, Morioka H, Petralia RS (1994) Light and electron microscopic immunocytochemical localization of AMPAselective glutamate receptors in the rat spinal cord. J Comp Neurol 344:431-454

Valtschanoff JG, Phend KD, Bernardi PS, Weinberg RJ, Rustioni A (1994) Amino acid immunocytochemistry of primary afferent terminals in the rat dorsal horn. J Comp Neurol 346:237-252.

Vulchanova L, Olson TH, Stone LS, Riedl MS, Elde R, Honda CN (2001) Cytotoxic targeting of isolectin IB4-binding sensory neurons. Neuroscience 108:143-155.

Watanabe M, Mishina M, Inoue Y (1994) Distinct gene expression of the $N$-methyl-D-aspartate receptor channel subunit in peripheral neurons of the mouse sensory ganglia and adrenal gland. Neurosci Lett 165:183-186.

Wenthold RJ, Yokotani N, Doi K, Wada K (1992) Immunocytochemical characterization of the non-NMDA glutamate receptors subunitspecific antibodies: evidence for a hetero-oligomeric structure in rat brain. J Biol Chem 267:501-507.

Westbrook GL, Lothman EW (1983) Cellular and synaptic basis of kainic acid-induced hippocampal epileptiform activity. Brain Res 273:97-109

Willis Jr WD, Coggeshall ER (1991) Sensory mechanisms of the spinal cord. New York: Plenum.

Woodbury JC, Ritter AM, Koerber HR (2000) On the problem of lamination in the superficial dorsal horn of mammals: a reappraisal of the substantia gelatinosa in postnatal life. J Comp Neurol 417:88-102.

Ye Z, Westlund KN (1996) Ultrastructural localization of glutamate receptor subunits (NMDAR1, AMPA GluR1 and GluR2/3) and spinothalamic tract cells. NeuroReport 7:2581-2585. 